the e-retail sector. A follow-up study 'Regulating the OSH impact of the online platform economy' describes the related OSH risks, highlights the challenges for current regulatory approaches on OSH and presents examples of approaches being developed to meet these challenges.

Discussion The future can evolve in different directions shaped by the actions and decisions of various players taken today. EU-OSHA intends to inform and stimulate debate on the future of work among experts and policy-makers to ensure safe and healthy workplaces in the future.

\section{7d FUTURE OF WORK AND OCCUPATIONAL HEALTH - A GLOBAL VIEW FROM THE ILO}

Nancy Leppink. International Labour Organisation, Switzerland

\subsection{6/oemed-2018-ICOHabstracts.625}

Introduction Summary and key 'takeaways' from ILO global conversations on the Future of Work and their implications for occupational safety and health

Discussion Over that last two years the ILO has support global conversations on the Future of Work. These conversations have focused on four topics:

- work and society,

- jobs of the future,

- organisation of work and production, and

- governance of work.

These conversations identified for key drivers of changes in the world of work -technology, demography, climate change and globalisation. Each of these conversations and the drivers of change they identified have implications for occupational safety and health and the strategies that have been developed over the last decades to improve the safety and health of work and workplaces - from government regulation to workplace management systems. For decades, we have been reacting to the growing body of evidence on work-related hazards and their impact on workers' health and safety. Our energies have been focused on retrofitting work and workplaces to eliminate hazards after significant harm has already been done.

And as the body of evidence on occupational safety and health hazards has grown and its scope expanded beyond physical, biological, and chemical hazards, to psychosocial hazards and hazard related to work organisation, we must now presume that all work has an impact on worker health and safety and when we create the future of work we can no longer have 'a wait and see' attitude. We must anticipate the impact that future jobs will have on the safety and health of workers and this responsibility does not rest only with governments, employers and workers but with technology developers, equipment and chemical manufacturers, architects and the workplace designers, and human resource professionals as well as OSH professionals. For the ILO this may mean rethinking how it develops OSH standards and supports their implementation by its Member States.

\section{1 PROMOTING OSH STRATEGIES FOR GLOBAL END TB EFFORTS AMONG SILICA-EXPOSED WORKERS AND HEALTHCARE WORKERS}

MA Fingerhut, P Gottesfeld. International Commission on Occupational Health (ICOH)

10.1136/oemed-2018-ICOHabstracts.626

Aim of session Tuberculosis is the greatest public health challenge today. The global health community is actively planning strategies to End TB by 2030, and the occupational health community can play an important role in contributing solutions to prevent TB in high-risk worker populations. This session will review the evidence for the high prevalence of TB among health care workers and silica-exposed workers and outline the practical strategies for reducing these risks. Partners will be sought to engage governments and global health funders to invest in prevention strategies, and to offer assistance to countries in the future to carry out the OSH actions.

Despite decades of global efforts to end tuberculosis (TB), it is still 9th in the top ten causes of death globally, with 10.4 million new cases occurring in 2016. In September 2018 the UN General Assembly will hold a high-level meeting on TB. A preparatory Global Ministerial Meeting was held in Moscow in November 2017. Because it is well established that occupational risk factors contribute to the $\mathrm{TB}$ epidemic, $\mathrm{ICOH}$ participated in the Moscow Meeting. ICOH members reached out to health ministers to include occupational safety and health $(\mathrm{OSH})$ measures to prevent $\mathrm{TB}$ cases by reducing respirable silica dust exposures and taking actions to protect healthcare workers from occupational TB infections. This $\mathrm{OSH}$ focus adds additional approaches to the current focus on improving effective medication, which also prevents new TB cases. The Moscow Declaration now includes health care workers, care givers, miners and other workers exposed to silica dust as high risk TB populations. In some high burden TB countries, health care workers have almost a 4-fold incidence of TB compared to the general population. Studies have shown that silica dust exposure increases risk of acquiring TB up to 4-fold, and combined silicosis and HIV in miners increases risk of acquiring active TB by 15 times. Because respirable silica is an IARC Group 1 carcinogen, reduction prevents both cancer and TB. Discussions at the Moscow Meeting appreciated the addition of $\mathrm{OSH}$ preventive measures. However, more effort is required to bring governments and global health funders on board to recognise that working conditions and silica dust are significant risk factors for TB that must be addressed as part of a comprehensive strategy. To take these efforts forward, ICOH has formed two Stop TB component efforts: TB-HCW and Silica-TB. Discussions in this Workshop will bring together partners and plans to succeed.

\section{1a PREVENTING TUBERCULOSIS WITH SILICA DUST CONTROLS}

P Gottesfeld. Occupational Knowledge International, San Francisco, CA USA

10.1136/oemed-2018-ICOHabstracts.627 